doi:10.4149/neo_2012_072

\title{
Lung cancer in a Czech cohort exposed to radon in dwellings - 50 years of follow-up
}

\author{
L. TOMASEK \\ National Radiation Protection Institute, Prague 4, Bartoskova 28, Czech Republic \\ Correspondence: ladislav.tomasek@suro.cz
}

Received February 9, 2012 / Accepted April 10, 2012

\begin{abstract}
The presented study reports lung cancer mortality in a cohort of 11842 subjects exposed to high levels of radon covering the period 1961-2010. Exposure estimates were based on one year measurements of radon progeny in most houses of the study area (72\%), missing values in the studied area were replaced by measurements in proxy houses (9\%) and exposures outside the area (19\%) were based on country radon mapping. Mean concentration of $448 \mathrm{~Bq} \mathrm{~m}^{-3}$ in the study is higher than the country mean by a factor of 5 .

By 2010, a total of 293 lung cancers were observed. The risk is significantly related to cumulated exposure with ERR/100Bq $\mathrm{m}^{-3} 0.11$ (90\%CI: $0.04-0.25$ ). This value is consistent with the risk coefficients in other indoor studies and also with the risks observed among uranium miners. The present follow-up demonstrated that increased incidence of lung cancer depends mainly on exposure from previous 5-19 years. The relative risk of lung cancer in the present study derived from this model is 1.53 (90\%CI: $1.39-1.69)$.
\end{abstract}

Key words: residential radon, lung cancer, cohort study

The first epidemiological evidence on lung cancer risk in relation to cumulated exposure to radon was reported by Archer et al in 1964 [1]. In Czechoslovakia, first results on uranium miners were published in 1971 by Sevc [2]. About 20 years later, Sevc also established a cohort study in a population exposed to high levels of radon in dwellings. First results of this study with the follow-up 1961-1999 were published in 2001 [3]. Since then the follow-up has been extended by 11 years and these results are reported here.

\section{Patients and methods}

Study area and population. The study was established in 1990 as a retro-prospective follow-up covering period since 1961. The study area - Mid-Bohemia Pluton - is mostly granitoid with considerable breaks. The area of the study covers about $240 \mathrm{~km}^{2}$ (Figure 1). The levels of radon concentration in the selected area are considerably higher than in the rest of the country. The study population includes inhabitants of the area (80 villages) who by 1990 had resided in the area for at least 3 years (one of these years after 1960), who were alive by the end of 1960 or were born later. The collected individual data included date of birth, addresses of past residences, smoking habits, and housing characteristics. Data on 11992 subjects were collected by trained interviewers who also installed radon detectors.

Follow-up. Information on vital status were obtained from the Czech population registry at the Ministry of the Interior. In the period 1961-1999, the causes of death were obtained from registries of deaths at local administrative offices. In the period 2000-2010, diagnoses were obtained from the Institute of Health Information and Statistics of the Czech Republic. All causes of death were recoded according to ICD-9, which was used in previous analyses of the cohort.

Follow-up for each subject started at the latest of the following dates: three years after first year of recorded residence in the study area or 1 January 1961. The follow-up ended at the earliest of date of death, emigration, loss to follow-up, or 1 January 2011. Observed numbers of deaths were compared to expected numbers of deaths that were derived from annual publications of the Czech Statistical Office stratifying on age, gender, and calendar year according to the structure of the cohort. Standardized mortality ratios (SMR) for different categories of causes of death were corrected for missing causes of deaths as follows: 


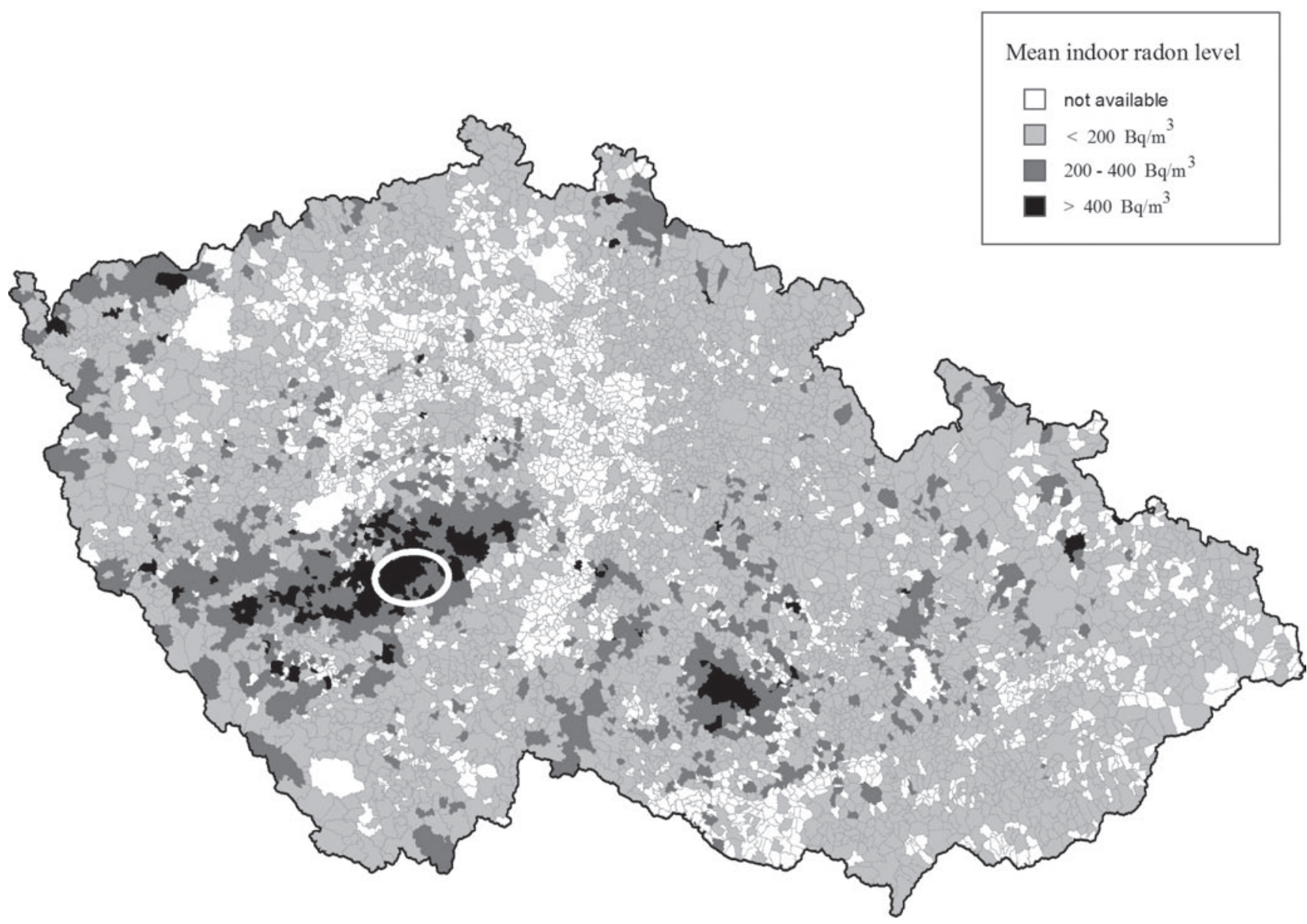

Figure 1. Radon concentrations in the Czech Republic and the study area (data from the Radon Program of the Czech Republic, 2010)

$\operatorname{SMR}=(\mathrm{O} / \mathrm{E}) / \mathrm{q}$ $\mathrm{q}=\mathrm{O}_{\text {known causes }} / \mathrm{O}_{\text {all causes }}$

where $\mathrm{O}$ denotes observed numbers and $\mathrm{E}$ expected numbers derived from national statistics. This correction was applied specifically at each category of age, calendar period, sex or cumulated exposure to radon.

Statistical methods. Analyses of the association between the risk of lung cancer and cumulated exposure to radon are based on the relative risk model, where the observed risk (R) of lung cancer is the product of baseline risk $\left(\mathrm{R}_{0}\right)$ and relative risk (RR).

\section{$\mathrm{R}=\mathrm{R}_{0} \mathrm{RR}$}

In general, the size of baseline risk is proportional to personyears and spontaneous (background) rates corresponding to an unexposed population, which is internally estimated in the cohort. Alternatively, the size of baseline risk can be assumed to be proportional to expected numbers that are derived from person-years and from national mortality rates. In both approaches, baseline rates are estimated for each level of strata defined by age, calendar year, sex, and smoking categories. The approach based on expected numbers makes use of age- specific mortality in the general population, although national and cohort baseline rates are not assumed to be equal. The estimated baseline risk generally depends on the model as it is based on the projection of the model to zero exposure.

The analyses were based on excess relative risk (ERR) models, where :

$\mathrm{RR}=1+\mathrm{ERR}$.

Similarly as in other residential studies on lung cancer and radon, the general dependence on cumulated exposure was considered for cumulated exposure within the so called exposure windows, usually 5-34 years before the current time of evaluation. This window reflects the so called minimum latency period ( 5 years in lung cancer and radon studies) and the fact that practically no effect has been observed from exposures before more than 35 years. Alternatively and for comparison to results of American and Chinese studies, the analyses were also conducted for models with exposure window 5-29 years. For comparison to occupational studies, where the exposures coved periods of about 50 years, the risk in the present study is also evaluated for exposures in the period 5-49 years. As the risk is known to decrease with time, the simple models with 
one cumulated exposure variable were complemented by two time specific exposure windows - 5-19 and 20-34 years. The models were therefore considered as follows:

$$
\begin{aligned}
& \mathrm{RR}=1+\mathrm{b}_{5-34} \mathrm{~W}_{5-34} \\
& \mathrm{RR}=1+\mathrm{b}_{5-19} \mathrm{~W}_{5-19}+\mathrm{b}_{20-34} \mathrm{~W}_{20-34},
\end{aligned}
$$

where variables $\mathrm{W}$ stand for cumulated exposure in $\mathrm{kBq} \mathrm{m}^{-3}$ years within respective exposure windows and parameters $\mathrm{b}$ are the estimates of excess relative risk per unit exposure.

Person-years of follow-up, observed numbers of cases were cross-classified by attained age, calendar year, sex, smoking categories, and different exposure windows. The parameters in Poisson regression models were estimated by the maximum likelihood method stratifying by age, calendar year, sex, and smoking categories. The fit between the model and the observed data is characterized by the so-called deviance. where lower values indicate better fit. The analyses were conducted using software Epicure [4].

Exposure estimation. The exposure assessment was based on measurements of equivalent equilibrium concentrations of radon (radon progeny) in most houses (80\%) of the study area. During the period 1991-92, usually two integral detectors (Kodak LR115) were installed for one year in two mostly occupied rooms of the house. In order to compare results to other residential studies, which are related to radon gas rather than radon progeny, values of equivalent equilibrium concentrations of radon were converted using 652 simultaneous measurements of radon progeny by passive track detectors and radon gas by electrets and closed CR-39 detectors. All results are given in terms of radon gas concentrations.

In the study area, the measurements were conducted in 2154 houses (mean $499 \mathrm{~Bq} / \mathrm{m} 3$ ). Measured exposures were available for $72 \%$ of residential person years. For houses in the study area that could not be measured (9\%), community means were used instead of missing values (mean $551 \mathrm{~Bq} / \mathrm{m} 3$ ). Exposure estimates in residences outside the study area were derived from a large scale mapping of radon in the Czech Republic conducted within the national Radon program. Concentrations corresponding to residences outside the study area $(19 \%$ of respective residential person-years in relevant exposure window 5-34 years) were estimated by larger community means for inhabitants in neighboring four districts (mean $267 \mathrm{~Bq} / \mathrm{m} 3$ ) and by district means for the residences in other districts, where concentrations were usually much lower (mean $163 \mathrm{~Bq} / \mathrm{m} 3$ ). These different approaches reflect numbers of subjects residing in different areas.

\section{Results}

A total of 11842 people (5858 men and 5984 women) satisfied the cohort criteria (permanent residence for at least 3 years in the study area, being alive on 1 January 1961 or born later). By the end of 2010, a total of 5114 (43\%) subjects died, 6619 (56\%) were alive, and only $109(1 \%)$ were lost to follow-up. Summary of vital status of the cohort is given in Table 1.

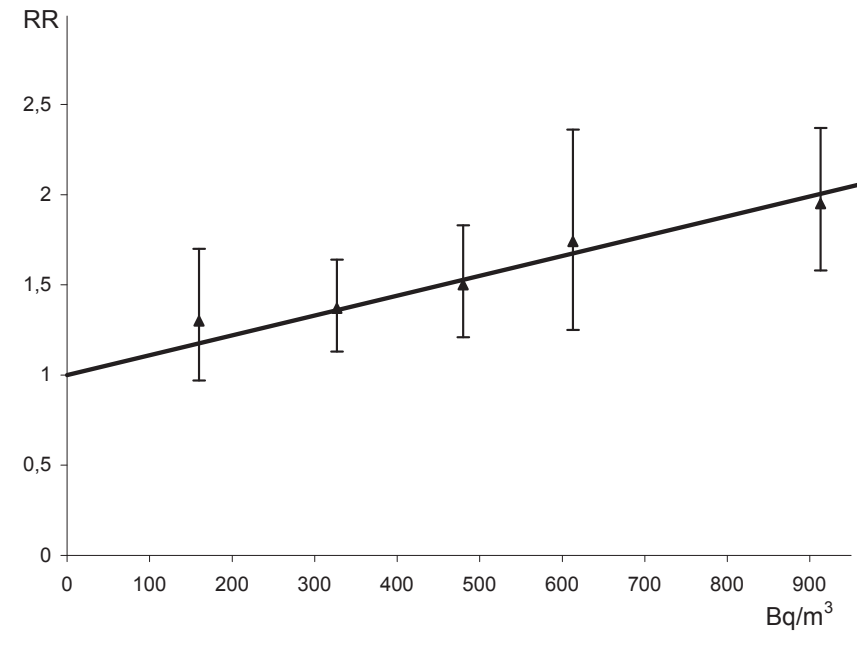

Figure 2. Lung cancer relative risk (RR) in dependence on average cumulated radon exposure from exposure window 5-19 $\left(\mathrm{Bq} / \mathrm{m}^{3}\right)$

Mortality. Specific mortality in the cohort was evaluated in categories of calendar period, age, sex, smoking, and cumulated exposure within exposure windows 5-34 years. Exposure categories are given in terms of average exposure during this exposure window. The specific mortality is given for all causes, lung cancer (ICD-9: 162), cancers other than lung cancer (ICD-9: 140-161, 163-208), other diseases (ICD9: 210-799), and external causes (ICD-9: 800-999). Numbers of deaths and standardized mortality ratios corrected for missing causes, including correction factors $\mathrm{q}$ are given in Table 2.

From the total of 5114 deceased subjects, a total of 293 lung cancers have been observed (Table 2). Generally for most categories of age or calendar period, the cause specific mortality in the cohort is somewhat lower in comparison to the general population of the Czech Republic, which is typical for rural population. The exception is lung cancer after 1970, particularly in the male population (SMR=1.24). Lung cancer mortality in women is much lower (SMR $=0.97$ ), most likely reflecting lower prevalence of smoking. Lower numbers in the 1960s might probably reflect lower level of diagnostics in the rural population of the study in comparison to national data.

Table 1. Summary of vital status of the cohort by the end of 2010

\begin{tabular}{lcc}
\hline Vital status & $\begin{array}{c}\text { number of } \\
\text { subjects }\end{array}$ \\
\hline deceased & 5114 & $43 \%$ \\
alive & 6619 & $56 \%$ \\
lost to follow-up & 68 & $0.6 \%$ \\
emigrated & 18 & $0.2 \%$ \\
residence in Slovakia after 2000 & 23 & $0.2 \%$ \\
\hline total & 11842 & \\
\hline
\end{tabular}


Table 2. Specific mortality in the cohort

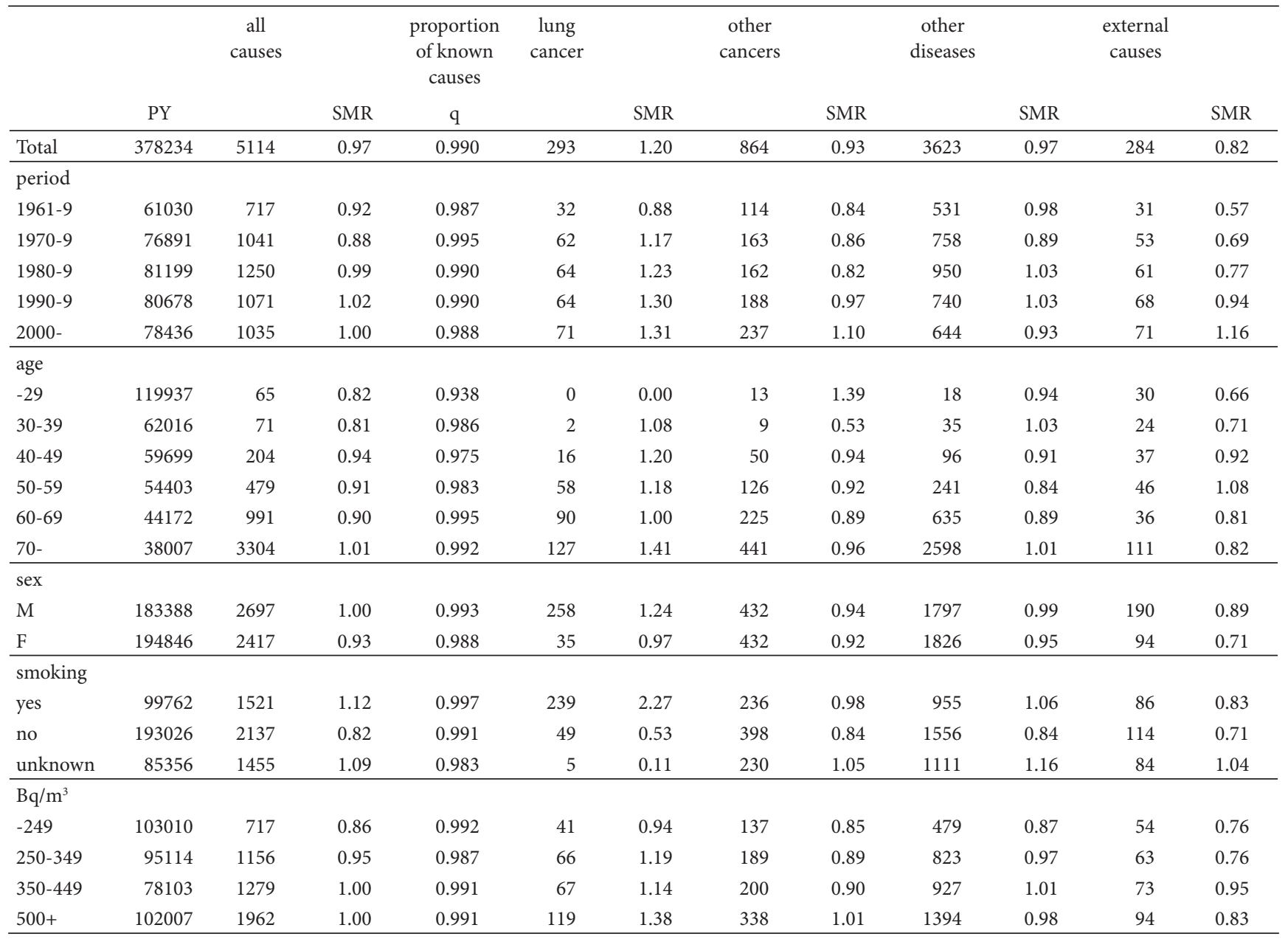

$\mathrm{PY}=$ person-years of follow-up

$\mathrm{SMR}=$ standardized mortality ratio, corrected for missing causes of death

$\mathrm{q}=$ correction factor

Table 3. Estimates of excess relative risk per unit cumulated exposure (ERR/kBq $\left.\mathbf{m}^{-3} \mathrm{y}\right)$ in models with different exposure windows

\begin{tabular}{|c|c|c|c|c|c|c|}
\hline model & $\begin{array}{l}\text { exposure } \\
\text { window }\end{array}$ & $\mathrm{ERR} / \mathrm{kB} \mathrm{m}^{-3} \mathrm{y}$ & $90 \% \mathrm{CI}$ & $\mathrm{p}$ & deviance & $\begin{array}{c}\text { baseline } \\
\text { lung cancers }\end{array}$ \\
\hline 1a & $5-49$ & 0.0205 & $0.0048-0.0503$ & 0.016 & 809.63 & 202.59 \\
\hline $2 \mathrm{a}$ & $5-19$ & 0.0769 & $0.0266-0.1715$ & 0.002 & 806.18 & 188.21 \\
\hline \multirow[t]{2}{*}{$3 a$} & $5-19$ & 0.1088 & $0.0387-0.1826$ & 0.005 & 804.82 & 207.95 \\
\hline & $20-49$ & -0.0261 & $-0.0547-0.0026$ & & & \\
\hline $1 b$ & $5-34$ & 0.0351 & $0.0110-0.0801$ & 0.005 & 676.20 & 194.11 \\
\hline $2 b$ & $5-19$ & 0.0734 & $0.0246-0.1642$ & 0.003 & 675.40 & 191.34 \\
\hline \multirow[t]{2}{*}{$3 b$} & $5-19$ & 0.0784 & $-0.0016-0.1686$ & 0.013 & 675.39 & 192.26 \\
\hline & $20-34$ & -0.0060 & $-0.0852-0.0807$ & & & \\
\hline $1 c$ & $5-29$ & 0.0345 & $0.0095-0.0798$ & 0.010 & 687.09 & 206.81 \\
\hline $2 c$ & $5-19$ & 0.0586 & $0.0166-0.1346$ & 0.009 & 686.86 & 205.69 \\
\hline \multirow[t]{2}{*}{$3 c$} & $5-19$ & 0.0585 & $-0.0229-0.1482$ & 0.033 & 686.86 & 205.67 \\
\hline & $20-29$ & 0.0002 & $-0.1223-0.1227$ & & & \\
\hline
\end{tabular}

deviance $=$ measure of fit between the data and the model 
Lung cancer risk in dependence on cumulated exposure. Lung cancer risk related to cumulated exposure for different exposure windows is given in Table 3. In addition to estimates of excess relative risk per unit exposure and corresponding confidence intervals for separate exposure windows, the table contains values of deviance, which for each model describe the fit between the observed data and the model (lower values correspond to better fit). The last column in the table contains baseline lung cancers estimated from each model.

Estimates based on models 1a, 2a, and 3a are given for comparison to studies of miners which cover lifetime exposure (50 years). The best estimate of excess relative risk from cumulated exposure is from model $2 \mathrm{~b}$, which corresponds to $\mathrm{ERR} / 100 \mathrm{~Bq} \mathrm{~m}{ }^{-3} 0.110$ (90\%CI: $0.037-0.246$ ). This coefficient is very similar to the value derived from model $1 \mathrm{~b}-0.105$ (90\%CI: $0.033-0.240)$. Models $3 \mathrm{a}, 3 \mathrm{~b}$, and $3 \mathrm{c}$ are attempts to estimate the contribution from more distant exposure, but these contributions were not significant in these models. The negligible contribution to the risk from previous exposure in 20-49, 20-34, or 20-29 years correspond to recent results in uranium miners, where in the multiplicative model the effect from exposures before more than 20 years was lower by factor of 5 for the same exposure window 5-19 years -0.027 and 0.005 , respectively [5]. Using model $2 \mathrm{~b}$ and estimated baseline value, the relative risk in the whole study is 1.53 (90\%CI: 1.39 $-1.69)$.

Comparison to the risk in other residential studies. At present, results from 3 pooled residential studies (European [6], North American [7], and Chinese [8]) are available, their estimates of excess relative risk are given in Table 4. Although the exposure windows are somewhat different, it is possible to derive a joint estimate using meta analysis which is 0.092 (90\%CI: 0.04-0.19).

Comparison of risks in the present study and risks in uranium miners. The risks from radon in residential and occupational studies are quantified differently because units of exposures are different. Therefore, a direct comparison is not obvious. One possibility is to convert exposure units into the same units. As the risk depends not only to volume activity and duration of exposure but also to breathing rates, the correct quantity is the cumulated intake. Another parameter to be considered is the equilibrium factor (F) characterizing volume activity of radon decay products in relation to the activity of radon gas. In occupational stud-

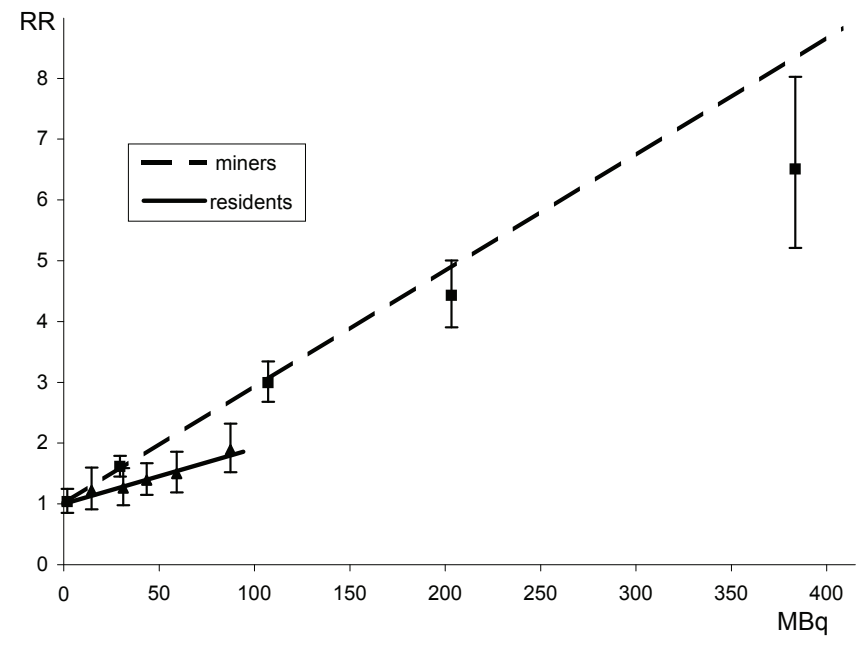

Figure 3. Lung cancer relative risks (RR) among residents and miners in dependence on cumulated intake of radon ( $\mathrm{MBq}$ )

ies, the exposure is already expressed in terms of radon decay products (WLM $=100 \mathrm{pCi} / \mathrm{L}$ for $170 \mathrm{~h}$ ). Therefore, for residential studies it is necessary to assume an equilibrium factor. According to the BEIR VI report [9], the best estimate of $\mathrm{F}$ is 0.4. Another assumption in residential studies is related to occupancy in dwellings. The best estimate of this parameter is 7000 hours per year [9]. The last assumption is on breathing rates: in occupational studies, the average breathing rate is $1.2 \mathrm{~m}^{3} / \mathrm{h}$, whereas in residential studies this value is $0.8 \mathrm{~m}^{3} / \mathrm{h}$. Using all these assumptions, it can be derived that

$1 \mathrm{kBq} / \mathrm{m}^{3} \mathrm{y}=1000 \mathrm{~Bq} / \mathrm{m}^{3} \times 0.4 \times 7000 \mathrm{~h} \times 0.8 \mathrm{~m}^{3} / \mathrm{h}=2.24 \mathrm{MBq}$, $1 \mathrm{WLM}=37 \mathrm{~Bq} / \mathrm{m}^{3} \times 170 \mathrm{~h} \times 1.2 \mathrm{~m}^{3} / \mathrm{h}=0.755 \mathrm{MBq}$.

Graphical comparison of residential and occupational risks in dependence on cumulated intake is given in Fig. 3. Here, the risks among uranium miners were taken from a Czech study of uranium miners [5]. Despite of substantial differences in cumulated exposure, both risks are compatible in terms of slopes. It should be noted that the risk in residential studies is largely influenced by uncertainty of exposures. When this issue is considered, the excess relative risk per unit exposure is about twice as it was shown by Darby et al [6]. The differences in exposure - about one order of magnitude - also illustrate the statistical power to detect the risk from radon.

Table 4. Results of 3 pooled residential studies

\begin{tabular}{lccccc}
\hline Study & Cases & $\begin{array}{c}\text { Exposure } \\
\text { window }\end{array}$ & ERR/100Bq/m & $95 \%$ CI & reference \\
\hline European & 7148 & $5-34$ & 0.084 & $0.030-0.158$ & Darby et al, 2006 \\
North American & 3662 & $5-30$ & 0.106 & $0.00-0.28$ & Krewski et al, 2005 \\
Chinese & 1050 & $5-30$ & 0.133 & $0.01-0.36$ & Lubin et al, 2004 \\
\hline meta analysis & & 0.092 & $0.04-0.19$ & \\
\hline
\end{tabular}




\section{Discussion}

Epidemiological evidence of lung cancer risk from radon is based mainly on studies of men employed underground in mines. Direct estimation of risk from residential radon is more complex than in occupational studies. As exposures in houses are by one order lower, such studies need larger numbers of cases. In addition, exposure estimates show higher uncertainty than in studies of miners. Errors in exposure estimates are unavoidable. The concentrations of radon vary substantially in time and location. Moreover, in most studies recent exposures are estimated with higher accuracy than those in the past. Estimates of cumulated exposure in occupational studies are generally more precise; not only because the radon measurements in mines were conducted already in the past, but also because the duration of stay of workers underground was recorded with a higher precision. This might be one of the reasons why separate studies on residential radon have not clearly demonstrated the effect of radon on lung cancer risk in the general population. In order to estimate the risk from indoor radon, much larger studies are necessary.

In evaluating the observed numbers of lung cancer deaths in the study, comparisons were done to expected numbers that were derived from the national statistics. Potential differences between the study population and the Czech population were accounted for by using the multiplicative correction term (parameters $\mathrm{c}_{\mathrm{i}}$ ) in strata defined by calendar period, sex, age, and smoking categories. Estimated values of this correction factor (in average 0.78 ) reflect low prevalence of smoking in the cohort, particularly in women. This lower relative figure also reflects mostly rural character of the study population. However, some effect of lower level of diagnostics, particularly in early years of follow-up cannot be excluded.

Lung cancer data in the present study were obtained from local and national registries, without any information on details of diagnoses like histological type or stage of cancer. For these reasons, no analyses on possible influence of these factors could be conducted.

In terms of size, the present study based on nearly 12000 people is one of the largest studies of lung cancer and radon. Other studies on radon are almost based on the case-control design, which allows to record individual habits and exposures as for instance in other indoor radon studies [6]. In the European joint study, some effect was observed among nonsmokers in relation to occupational exposures known to be associated with lung cancer risk [6]. In the present study, the effect of occupational exposure in uranium mines was eliminated, because such subjects were excluded from the study. Because of the size of the study, it was not possible to record individual data on exposure to other potential carcinogens, life style, or family factors. In the present study, we only analyzed exposures from radon and smoking. As the study area is mostly rural, other environmental exposures like industrial pollution are not believed to be of importance.
Consideration of smoking in evaluation of lung cancer risk is essential. Data on smoking in the cohort have been obtained for $78 \%$ subjects older than 15 years in person or from relatives. Separate estimates of ERR/ $\mathrm{kBqm}^{-3} \mathrm{y}$ for smokers and non-smokers have not been estimated due to low numbers of non-smokers.

The present estimated excess relative risk at $100 \mathrm{~Bq} \mathrm{~m}^{-3}$ -0.11 (90\%CI: 0.03-0.24) is consistent with results from other residential studies (meta analysis) 0.09, 95\%CI: 0.04-0.19). These estimates relate the risk to radon exposure without any correction to the variability of radon levels.

In the present study, we attempted to evaluate the decrease of the risk with time since exposure, which was observed in studies of uranium miners. In contrast to studies of uranium miners, in residential studies, the statistical power to detect the significant contribution from exposures received in previous 20-34 years is limited because of lower numbers of cancers in the present study, and because of generally lower cumulated exposures. These estimates are also embarrassed by correlation between exposures in the two windows.

Strengths and limitations. The main advantage of the present study is extensive long term measurements of radon in most houses of the study area. One year measurements are substantially better than measurement conducted for several months. The coefficient of variation of short term measurement is about $50 \%$, whereas values for one-year measurement are $36 \%$ [6]. Another advantage of the present study is the type of the study, because in cohort studies the selection bias is eliminated. Limitations of the study include low numbers of lung cancer cases, relatively large proportion of unknown smoking data, and missing measurements in some residences. These, however, can be rectified in future by extending follow up and completing of smoking and exposure data in the cohort. In addition, uncertainty of exposures, which is currently in the process of evaluation [10], can be evaluated for its effect on risk estimates.

\section{Conclusions and perspectives}

The study confirmed that the risk from radon exposure in houses is indubitable. Relative risk derived from the recent follow-up is consistent with other residential studies and with results observed among uranium miners. This risk depends mostly on exposures received during preceding last 20 years. Future efforts in the present study will aim at improving smoking data and data on exposure. Possibilities to use data on cancer incidence from national cancer registry will be examined.

Acknowledgements: The author wishes to thank Dr Alena Heribanova and Ivanka Zachariasova from the State Office for Nuclear Safety for their continuing support in conducting the study, the Population Registry at the Czech Ministry of the Interior and the Institute of Health Information and Statistics of the Czech Republic for providing individual mortality data. The author also thanks to Dr Tomas Muller for inspection of causes of death, Ivana Fojtikova for radon 
mapping, and Milana Rendlova for data management. Finally, the author would also like to thank to prof. Vladislav Klener for his valuable comments to the paper. The study was supported by the Czech Ministry of Health (project NS/10596-3).

\section{References}

[1] ARCHER VE, MAGNUSON HJ, HOLADAY DA, LAWRENCE PA Hazards to health in uranium mining and milling. J Occup Med 1962; 4: 55-60.

[2] SEVC J, PLACEK V, JERABEK J Lung cancer risk in relation to long-term radiation exposure in uranium mines. In: Proceedings of 4th Conference on Radiation Hygiene, T. Trnovec and P. Gaal (eds.), Jasna pod Chopkom, Slovakia, 1971, 315-326.

[3] TOMASEK L, MULLER T, KUNZ E, HERIBANOVA A, MATZNER J et al. Study of lung cancer and residential radon in the Czech Republic. Cent Eur J Public Health 2001; 9: 150-153.

[4] PRESTON DL, LUBIN JH, PIERCE DA, MCCONNEY ME Epicure, release 2.10. HiroSoft Int. Corp., Seattle, 1998.

[5] TOMASEK L Interaction of radon and smoking among Czech uranium miners. Radiat Prot Dosim 2011; 145: 238-242. http://dx.doi.org/10.1093/rpd/ncr048
[6] DARBY S, HILL D, DEO H, AUVINEN A, BARROS-DIOS JM et al. Residential radon and lung cancer - Detailed results of a collaborative analysis of individual data on 7148 persons with lung cancer and 14208 persons without lung cancer from 13 epidemiologic studies in Europe. Scand J Work Environ Health 2006; Suppl 32: 1-84.

[7] KREWSKI D, LUBIN JH, ZIELINSKI JM, ALAVANJA M, CATALAN VS et al. Residential radon and risk of lung cancer - a combined analysis of 7 North American case-control studies. Epidemiology 2005; 16: 137-145. http://dx.doi. org/10.1097/01.ede.0000152522.80261.e3

[8] LUBIN JH, WANG ZY, BOICE JD, XU ZY, BLOT WJ et al. Risk of lung cancer and residential radon in China: Pooled results of two studies. Int J Cancer 2004; 109: 132-137. http://dx.doi. org/10.1002/ijc. 11683

[9] National Research Council, Committee on Biological Effects of Ionizing Radiation: Health Risks of Exposure to Radon (BEIR VI), National Academy Press, Washington DC, 1998.

[10] SLEZAKOVA M, NAVRATILOVA-ROVENSKA K, TOMASEK L, HOLECEK J Short- and long-term variability of radon progeny concentration in dwellings in the Czech Republic. Radiat Prot Dosim 2012, submitted. 